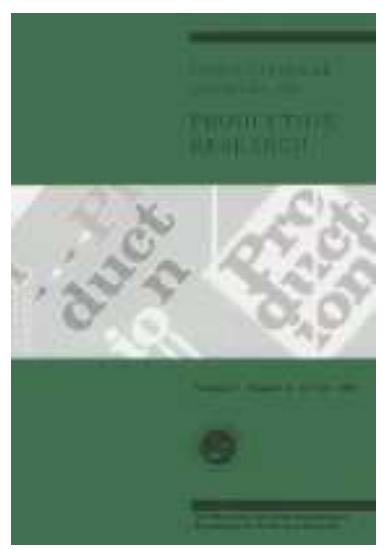

\title{
Dynamic buy-back for product recovery in end-of-life spare parts procurement
}

\begin{tabular}{|r|l|}
\hline Journal: & International Journal of Production Research \\
\hline Manuscript ID: & TPRS-2010-IJPR-0618.R1 \\
\hline Manuscript Type: & Original Manuscript \\
\hline Author: & 13-Dec-2010 \\
\hline Complete List of Authors: & $\begin{array}{l}\text { Kleber, Rainer; Otto-von-Guericke University Magdeburg, Faculty of } \\
\text { Economics and Management } \\
\text { Schulz, Tobias; Otto-von-Guericke University Magdeburg, Faculty of } \\
\text { Economics and Management } \\
\text { Voigt, Guido; Otto-von-Guericke University Magdeburg, Faculty of } \\
\text { Economics and Management }\end{array}$ \\
\hline Keywords: & INVENTORY MANAGEMENT, REVERSE LOGISTICS \\
\hline Keywords (user): & \\
\hline &
\end{tabular}

\section{SCHOLARONE Manuscripts}


International Journal of Production Research

Vol. 00, No. 00, 00 Month 200x, 1-16

\title{
RESEARCH ARTICLE
}

\section{Dynamic buy-back for product recovery in end-of-life spare parts procurement}

\author{
Rainer Kleber ${ }^{a *}$, Tobias $\operatorname{Schulz}^{a}$, and Guido Voigt ${ }^{a}$ \\ ${ }^{a}$ Otto-von-Guericke University Magdeburg, Germany \\ (Received 00 Month 200x; final version received 00 Month 200x)
}

\begin{abstract}
The efficient supply of spare parts is of prime concern for OEM's. While manufacturing the parent product, spare parts can be sourced efficiently by using existing manufacturing facilities. This situation completely changes once the OEM ceases production of the parent product. Next to traditional spare parts sources in form of final order and remanufacturing, the option to buy back parts or products provides a viable alternative in the end-of-life phase. This can prevent the OEM from fulfilling his spare parts availability obligation or increase his ability to remanufacture. Current practice in industry is on the one hand to offer trade-in campaigns to acquire functional products from customers by giving substantial discounts on a new generation product. On the other hand, trade-in rebates are given when customers return their broken parts in exchange for spare parts. We propose consideration of a third option, i.e. to buy back broken products in order to improve control demand for spare parts and supply of recoverable parts. This contribution seeks to assess the potential benefit of buy-back strategies in contrast to both traditional sourcing and trade-in campaigns for different settings regarding information availability and buy-back flexibility. For each situation, a MILP formulation is presented, and in a numerical study we analyze circumstances under which buy-back of broken products is especially beneficial for the OEM.
\end{abstract}

Keywords: Inventory Management, Spare Parts Management, Reverse Logistics, Buy-back, Trade-in

\section{Introduction}

In recent years, original equipment manufacturers (OEMs) of durable goods identified the after-sales market as one of their key business segments. For instance, a 1999 AMR Research report states that on average aftermarket business activities generate about $45 \%$ of their gross profits (see Cohen et al. 2006). Furthermore, a competitive advantage can be established if the OEM provides superior service to his customers, e.g. by guaranteeing

\footnotetext{
*Corresponding author. Email: rainer.kleber@ovgu.de
} 
the availability of spare parts during a comparably long service period. Thus, the length of this period becomes an important strategic parameter for management. The service period is subdivided into two distinct phases, the normal phase during which the primary product is manufactured and sold as well as the final phase. This phase starts when serial production ceases and can be considerably longer than the production period. In the automotive sector, for instance, the final phase lasts for 10-15 years. Yet, several OEMs promise a significantly longer availability of spare parts for premium products as the example of a 30 years service period for Mercedes-Benz cars indicates.

In a recent contribution, Kim and Park (2008) propose a model that allows to determine the optimal length of the final phase. They argue that the marketing department seeks to stimulate demand by offering a long service period as this signals a high quality of the product (see, e.g., Spence 1977, Gal-Or 1989). From an operations point of view, however, the final phase would be chosen considerably shorter when only accounting for the costs and revenues of providing spare parts. This contribution focuses on situations in which both perspectives (marketing and operations) yield large differences in the length of the service period.

Inventory management for spare parts differs considerably from inventory management applied to manufacturing processes, mainly because demand for spare parts is less predictable and highly dynamic on a comparably low level (see, e.g., Kennedy et al. 2002, Huiskonen 2001). In addition, options for re-supply become increasingly rare during the final phase. While in the normal phase production facilities of the primary product can be used, this efficient sourcing option is often no longer available since manufacturing facilities are used for new generation products. Thus, a frequently adopted strategy is to place a final order at the time when regular production comes to an end. However, this is connected with high stock levels resulting in large holding cost and a high obsolescence risk as all demands occurring in the final phase need to be estimated beforehand. Extra production represents an additional option which is under certain circumstances prohibitively expensive or technically infeasible (see Hesselbach et al. 2002, for a comprehensive overview on this issue).

There is a one-to-one correspondence between a spare part and the defective (or 'broken') component. This creates the opportunity to recover the defective part for later use as a spare part. An overview on different recovery processing options is provided by Thierry et al. (1995) including repair, refurbishing, and remanufacturing. Although all of these options could be applied to satisfy the demand for spare parts, remanufacturing is of special interest for the OEMs since remanufactured parts are considered to be as-good-as-new and therefore likely to be accepted by the customers. Remanufacturing can complement other sourcing options if a sufficient supply of recoverables is assured. For this purpose, a common method in practice is to buy back defective parts by giving a rebate on remanufactured spare parts only if the defective parts are returned to the OEM. Compared to extra production, remanufacturing is relatively cheap, but since not all broken parts might be remanufacturable it should be accompanied by other options to avoid shortages (see, e.g., Inderfurth and Mukherjee 2008, Inderfurth and Kleber 2009). A strategy including remanufacturing complemented by a final order is used as a benchmark in this work.

In case of not being able to fulfill all spare part demands towards the end of the final phase and in order to avoid a penalty or a goodwill loss, OEMs can offer further options including swapping and trade-in of the whole product. Swapping refers to a replacement of the dysfunctional product with a new generation product free of charge for the customer (as has been reported by Pourakbar et al. 2009). This option is favorable 


\section{Page 3 of 18 \\ International Journal of Production Research}

International Journal of Production Research

for high-tech products experiencing a considerable price deterioration between successive product generations but is less beneficial for durables. Trade-in of products is typically performed in the form of broadly advertised, time-limited campaigns. These campaigns intend to increase the sales of new products and, thus, also functional products are accepted. Although there are many examples from industry (see, e.g., Ray et al. 2005), an acquisition of products for satisfying spare part demands is (at best) seen as a side effect and is not explicitly stated as motivation for such a campaign.

In our study, we propose the use of more focused buy-back campaigns that specifically target on dysfunctional products requiring repair. Since the customers need to contact the OEM's service network in case of repair, this option could be implemented along with the buy-back of defective parts. In particular, we are interested in those conditions under which buying back broken products for obtaining spare parts profitably complements the traditional sourcing options final order and remanufacturing. An active integration of buying back used products into a generic product recovery system has been examined by Minner and Kiesmüller (2010) in a deterministic setting with a stationary price-response function. There, the effects of the acquisition decision on current and future demands are neglected. In our case, however, buying back would on the one hand decrease current and future demands for spare parts since there will be no future spare part demand generated from a bought back product. On the other hand, customers with a dysfunctional product might accept a comparably low compensation yielding a cheap supply of recoverable parts towards the end of the final phase. Therefore, the trade-off between cannibalizing current and future demands to release oneself from the obligation to provide spare parts and creating an additional source of supply for satisfying the remaining demand represents the main focus of this work.

The remainder is organized as follows. In Section 2 we introduce a basic model that integrates the buy-back of broken products in the decision-making process. Afterwards, in Section 3 a numerical example is used to demonstrate the possible benefit of buying back broken products in contrast to both a strategy where a final order is complemented only by the buy-back of broken parts and another where additionally trade-in campaigns are conducted. In doing so, we abstract from the above mentioned sales promoting effects for other products and isolate the sole effect of buying back broken products on spare parts management. In the fourth section we discuss the impact of additional buy-back related constraints. Furthermore, a sensitivity analysis is performed. Finally, Section 5 summarizes the main conclusions and gives some directions for future research.

\section{A basic model with buy-back}

We consider a single product for which the OEM guarantees the availability of spare parts during the final phase of service. The planning horizon of length $T$ starts at the end of regular production, i.e. at the time when no further products are manufactured and thus, the number of products with the customers (called install base) no longer increases. For the sake of simplicity, the considered product includes only one vital part or component that can fail and needs to be replaced by a spare part to restore the products functionality. Otherwise, the product's value would reduce considerably. Failures occur deterministically with rate $\lambda \in(0,1)$, i.e. each period a fraction of the install base requires spare parts to replace broken components. This is accomplished by the existing service network operated by the OEM which is also used to return broken components to a remanufacturing facility. The spare parts supply system is depicted in Figure 1. 
Demand for spare parts is satisfied from a central stock-keeping point. Let $B_{t}^{S}$ denote the OEM's spare parts stock at the end of period $t$ that can be replenished using two different options. At the beginning of the planning period, the OEM places a final order $F O$ at unit cost $c_{f}$. Afterwards, regular production ceases and remanufacturing broken components becomes the only sourcing option. The stock of recoverables $B_{t}^{R}$ is efficiently filled from broken parts in exchange for spare parts sold at a (net) price $p_{s}$. The parameters $h^{R}$ and $h^{S}$ represent the unit holding cost for broken parts and spare parts per period, respectively.

In each period $t$, the OEM must decide on the amount of broken components to remanufacture $R_{t}$ at unit cost $c_{r}$, on the quantity of broken components to dispose of $D_{t}$, and on the buy-back quantities. As is commonly presumed for practical applications, we suppose that revenues and costs for the material recovered are about the same size, i.e. disposal costs are negligible. Due to an imperfect remanufacturing process only a fraction $q \in(0,1]$ of the remanufactured products fulfill the designated quality standards to be sold as spare parts.

If the OEM decides to buy back the entire broken product, he loses the revenue for selling a spare part but he also increases the recoverables stock by one unit. The compensation paid to the customer depends on her valuation of the product, which might differ within the install base. Depending on the OEM's buy-back decisions the size and composition of the install base changes over time. This results in complicated dynamic relationships between current and future decisions. An appropriate method to incorporate decision dynamics would be to segment the install base into groups $i=1, \ldots, n$ in which all customers value their product similarly. The initial size of each segment $\bar{y}_{i}$ is known in advance and the number of functioning products in each customer segment $i$ at the end of period $t$ is denoted by $y_{i, t}$. Independent of the OEM's decisions a fraction $\nu_{i, t}$ of all products in customer segment $i$ leaves the service network. Let $p_{i}$ denote the reservation price of all customers in segment $i$ representing their valuation of a defective product. Without loss of generality, the customer segments are arranged such that inequality $p_{1}<\ldots<p_{n}$ is satisfied, providing the OEM with a set of candidates for buy-back prices. All costs and revenues are discounted by using the interest rate $r$. The notation is summarized in Table 1.

In an idealized setting (denoted by M1), the OEM decides for each segment separately which quantities to buy back for which price. This requires the OEM to assign each customer to her segment, i.e. individual customer information is available. Buy-back 


\section{December 13,2010 \\ International Journal of Production Research}

International Journal of Production Research

Table 1. Notation used

\begin{tabular}{ll}
\hline Parameters \\
\hline$n$ & Number of customer segments \\
$T$ & Planning horizon \\
$c_{r}$ & Unit cost of remanufacturing \\
$c_{f}$ & Final order unit cost \\
$h^{S}$ & Spare parts holding costs per unit and period \\
$h^{R}$ & Returned products holding costs per unit and period \\
$p_{i}$ & Reservation price in customer segment i \\
$p_{s}$ & Revenue per spare part sold \\
$q$ & Remanufacturing yield rate \\
$\lambda$ & Components failure rate \\
$r$ & Interest rate \\
$\bar{y}_{i}$ & Initial product stock in customer segment $i$ \\
$\bar{B}_{0}^{R}$ & Initial stock of broken products \\
$\nu_{i, t}$ & Percentage of products leaving the OEM's access of segment $i$ in period $t$ \\
\hline Decision and state variables \\
\hline$B_{t}^{S}$ & Spare parts inventory at the end of period $t$ \\
$B_{t}^{R}$ & Recoverables inventory at the end of period $t$ \\
$F O$ & Size of the final order \\
$R_{t}$ & Number of remanufactured parts in period $t$ \\
$D_{t}$ & Number of broken products disposed of in period $t$ \\
$E_{t}$ & Fulfilled spare part demand in period $t$ \\
$x_{i, j, t}$ & Number of broken products bought back from segment $i$ at price $p_{j}$ in period $t$ \\
$y_{i, t}$ & Number of customers in segment $i$ in period $t$ \\
\hline &
\end{tabular}

quantities are denoted by $x_{i, j, t}$ representing the number of broken products bought back from customer segment $i$ at price $p_{j}$ in period $t$. Consequently, each broken product bought back in period $t$ reduces the number of spare parts sold (denoted by $E_{t}$ ). Model M1 can be formulated as follows:

$$
\begin{aligned}
\max \Pi_{1} & =-c_{f} \cdot F O+\sum_{t=1}^{T}(1+r)^{-t}\left[p_{s} \cdot E_{t}-c_{r} \cdot R_{t}-h^{R} \cdot B_{t}^{R}-h^{S} \cdot B_{t}^{S}-\sum_{i=1}^{n} \sum_{j=1}^{n} x_{i, j, t} \cdot p_{j}\right] \\
\text { s.t. } & \\
E_{t} & =\lambda \sum_{i=1}^{n} y_{i, t-1}-\sum_{i=1}^{n} \sum_{j=1}^{n} x_{i, j, t} \quad t=1, \ldots, T \\
B_{0}^{S} & =F O \quad B_{t}^{S}=B_{t-1}^{S}-E_{t}+q \cdot R_{t} \quad t=1, \ldots, T \\
B_{0}^{R} & =\bar{B}_{0}^{R} \quad B_{t}^{R}=B_{t-1}^{R}-R_{t}-D_{t}+\lambda \cdot \sum_{i=1}^{n} y_{i, t-1} \quad t=1, \ldots, T \\
y_{i, 0} & =\bar{y}_{i} \quad i=1, \ldots, n \\
y_{i, t} & =y_{i, t-1} \cdot\left(1-\nu_{i, t}\right)-\sum_{j=1}^{n} x_{i, j, t} \quad i=1, \ldots, n \quad t=1, \ldots, T
\end{aligned}
$$




$$
\begin{aligned}
& \sum_{j=1}^{n} x_{i, j, t} \leq \lambda \cdot y_{i, t-1} \quad i=1, \ldots, n \quad t=1, \ldots, T \\
& x_{i, j, t}=0 \quad i, j=1, \ldots, n \quad j<i \\
& B_{t}^{S}, B_{t}^{R}, E_{t}, R_{t}, x_{i, j, t}, y_{i, t} \geq 0 \quad i, j=1, \ldots, n \quad t=1, \ldots, T
\end{aligned}
$$

The OEM's objective (1) is to maximize his discounted profit $\Pi_{1}$. This includes expenses for the final order, each period's revenue of selling $E_{t}$ spare parts, and out-ofpocket cost incurred for remanufacturing, stock-keeping, and buy-back. In restriction (2), the number of spare parts sold $E_{t}$ is determined by the amount of products requiring repair in $t$ reduced by the buy-back quantity. Constraints (3) and (4) are inventory balance equations for the spare parts and recoverables inventory with given initial levels. The initial spare parts stock equals the size of the final order. The stock of spare parts at the end of period $t B_{t}^{S}$ is calculated by reducing the stock at the end of the previous period $B_{t-1}^{S}$ by $E_{t}$ plus the yield from the remanufacturing process $q \cdot R_{t}$. Starting from an initial value $\bar{B}_{0}^{R}$, the stock of recoverables reduces by the number of remanufactured $R_{t}$ and disposed of parts $D_{t}$. It increases by the number of broken products returning to the OEM.

The number of products in each customer segment develops according to balance equation (6) while (5) represents their initial sizes. It reduces by the exogenous drain of leaving customers and the total number of bought-back products from the corresponding segment. Constraint (7) ensures that only products can be bought back which fail in the respective period. Logical constraint (8) guarantees that no buy-back occurs for a lower price than the segment specific reservation price. Non-negativity restrictions (9) assure validity of decisions.

The proposed model M1 is solved efficiently by using a standard package for linear optimization. It can be easily seen that the optimal solution of M1 will always show $x_{i, j, t}=0$ for $i \neq j$. Since the OEM can approach each customer individually, he offers her the corresponding reservation price.

\section{The value of buy-back}

In this section, a numerical example illustrates the potential benefit of buying back broken products compared to two other strategies. The first one is a benchmark situation (BM) without actively controlling spare parts demand, which only uses the final order and the buy-back of broken parts for remanufacturing. A second strategy additionally includes the trade-in of non-defective products (TI). After introducing the required changes to model M1 a base case scenario with a single customer segment is introduced and evaluated. Afterwards, we elaborate potential gains of a more detailed modeling of the install base by varying the number of customer segments.

\section{1. $\quad$ Modeling of alternative strategies}

While a solution for the benchmark situation (BM) could easily be obtained by forcing all buy-back quantities $x_{i, j, t}$ to zero in model M1, the option to trade in products currently in use by the customers (TI) requires several changes to the model. An additional binary decision variable $\Theta_{i, t}$ is introduced which represents the OEM's decision to offer a trade- 


\section{Page 7 of 18 \\ International Journal of Production Research}

International Journal of Production Research

in at price $\hat{p}_{i}$ in period $t$. In the objective (1), the buy-back price $p_{i}$ (at which the customer would sell the defective product) is substituted by a corresponding trade-in price $\hat{p}_{i}=p_{i}+p_{s}$, representing the price at which the customer is willing to sell the functional product. This assumption can be imposed since any defective product can be transformed into a functional one at a price $p_{s}$. Restrictions (2) and (7) have to be replaced by

$$
\begin{aligned}
E_{t} & =\lambda \sum_{i=1}^{n} y_{i, t-1} \quad t=1, \ldots, T \\
x_{i, j, t} & \leq M \cdot \Theta_{j, t} \quad i=1, \ldots, n \quad t=1, \ldots, T \\
y_{i, t-1} \cdot\left(1-\nu_{i, t}\right)-x_{i, j, t} & \leq M \cdot\left(1-\Theta_{j, t}\right) \quad i, j=1, \ldots, n \quad t=1, \ldots, T \\
\sum_{i=1}^{n} \Theta_{i, t} & \leq 1 \quad t=1, \ldots, T \\
\Theta_{i, t} & \in\{0,1\} \quad i=1, \ldots, n \quad t=1, \ldots, T
\end{aligned}
$$

Restriction (10) ensures that only functioning products are bought back (after repair if required). Constraint (12) ensures that all customers return their products to the OEM when $\Theta_{i, t}$ is set to one. In this case, all products remaining in segment $i$ after the drain are procured by the OEM. If, otherwise, $\Theta_{i, t}$ is set to 0 , restriction (11) forces the buyback quantity to 0 . Finally, restriction (13) guarantees that only one buy-back price is set by the OEM in period $t$.

\subsection{The value of buy-back without segmentation}

We start our analysis with a base case considering a single customer segment $(n=1)$ for which all spare part demands must be satisfied for the next $T=80$ periods. A period is hereby defined to be a quarter of a year which means the OEM faces a 20 year planning horizon. The OEM estimates the initial number of products in the install base to be $\bar{y}_{1}=400$ out of which a fraction of $\nu_{1}=1.5 \%$ are leaving the service network each period. The main component fails at a rate $\lambda=10 \%$, i.e. each product has to be repaired on average once in two and a half years yielding a revenue of $p_{s}=10$. The OEM estimates that a broken product can be acquired at a price of $p_{1}=20$ being twice the revenue from selling a spare part. Hence, the trade-in price for a functional product is given by $\hat{p}_{1}=30$.

Spare parts are procured by placing a final order at unit cost $c_{f}=3$ yielding an initial profit margin of $70 \%$. Broken parts returning to the OEM can be remanufactured at unit cost $c_{r}=1.5$. Remanufacturing is successful in $q=50 \%$ of the cases, i.e. one of two broken parts can be used further. Thus, there is no direct cost advantage for neither parts procured in the final order nor for parts succesfully remanufactured. The discount rate is set to $r=2.5 \%$ per quarter or about $10 \%$ per year. Out of pocket holding cost are $h^{S}=0.2$ and $h^{R}=0.1$ per unit and period for spare parts and recoverable parts, respectively. Taking both discounting and holding cost into account, it would be economically beneficial to satisfy demand from parts procured in the final order for at most 20 periods (5 years) and to switch to remanufacturing afterwards, given a sufficient supply of recoverables.

The main results are presented in Table 3. The benchmark situation (BM) shows a 
Table 2. Base case parameter values

\begin{tabular}{cccccccccccccc}
\hline$n$ & $T$ & $\bar{y}_{1}$ & $\nu_{1}$ & $\lambda$ & $p_{s}$ & $c_{f}$ & $c_{r}$ & $q$ & $r$ & $h^{S}$ & $h^{R}$ & $p_{1}$ & $\hat{p}_{1}$ \\
\hline 1 & 80 & 400 & $1.5 \%$ & $10 \%$ & 10 & 3 & 1.5 & $50 \%$ & $2.5 \%$ & 0.2 & 0.1 & 20 & 30 \\
\hline
\end{tabular}

Table 3. Optimal final order $F O$, discounted profit $\Pi$, relative profit surplus $\Delta$ and first period in which buy-back takes place $z$ in the benchmark, the trade-in solution, and for M1

\begin{tabular}{cccccccccc}
\hline \multicolumn{3}{c}{ Benchmark } & \multicolumn{3}{c}{ Optimal Trade-in } & \multicolumn{3}{c}{ Optimal buy-back in M1 } \\
$F O_{B M}$ & $\Pi_{B M}$ & $F O_{T I}$ & $\Pi_{T I}$ & $\Delta_{T I}$ & $F O_{1}$ & $z_{1}$ & $\Pi_{1}$ & $\Delta_{1}$ \\
\hline 935 & 2390 & 935 & 2390 & $0 \%$ & 658 & 46 & 3127 & $+30.8 \%$ \\
\hline
\end{tabular}

solution structure in which (as has been examined in a related approach by Kleber and Inderfurth 2007) two phases to be distinguished. In a first phase (periods 1 to 29) the demand for spare parts is satisfied from the final order of size $F O_{B M}=935$. All broken parts that return are held in the recoverables inventory and none is disposed of. In a second phase (periods 30 to 80 ) the strategic stock of returned parts built up in the first phase is remanufactured to serve demand. Since the first phase lasts for more than 20 periods, the base case parameters (summarized in Table 2) depict a situation in which the operations manager is confronted with a much longer final phase than he would choose individually. The benchmark solution yields a total discounted profit of 2390 .

In the single segment case, running a trade-in campaign (TI) would instantly deplete the whole install base. This provides a control on the length of the service period by balancing trade-in cost and future losses when having to satisfy demands. Since selling spare parts remains a profitable business opportunity for the OEM over the entire planning horizon, the solution does not deviate from the benchmark solution.

When including the option to buy back broken products using model M1, the final order reduces to 658 implying a substantial reduction in holding cost. Although considerably shorter (the first phase ends in period 19), both of the above phases are present. In an adjacent third phase (starting in period $z_{1}=46$ ), the OEM buys back the amount of broken products that just compensates the yield loss from remanufacturing broken parts. Due to the increased flexibility in controlling the install base the discounted profit rises by about $31 \%$ to 3127 .

\subsection{The value of customer segmentation}

Segmenting the install base w.r.t. differences in the customers' valuation of the product increases the flexibility for both trade-in and buy-back strategies. In order to assess the value of this flexibility, customer segments are created based on the trade-in or buy-back price, respectively. All other parameters remain the same as in the base case.

For determining the segment specific prices, the customers' valuation of the broken product is assumed to be uniformly distributed among the 400 customers in an interval 


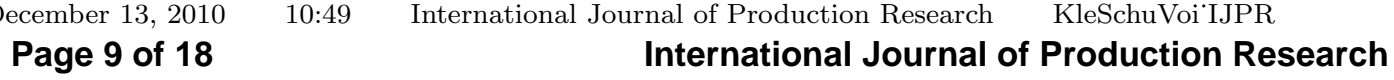

Table 4. Influence of the number of segments $n$ on the final order and discounted profit

\begin{tabular}{ccccccccc}
\hline & \multicolumn{3}{c}{ Optimal Trade-in } & \multicolumn{3}{c}{ Optimal buy-back in M1 } \\
$n$ & $F O_{T I}$ & $z_{T I}$ & $\Pi_{T I}$ & $\Delta_{T I}$ & $F O_{1}$ & $z_{1}$ & $\Pi_{1}$ & $\Delta_{1}$ \\
\hline 1 & 935 & $/$ & 2390 & $0 \%$ & 658 & 46 & 3127 & $+30.8 \%$ \\
2 & 848 & 56 & 2416 & $+1.1 \%$ & 621 & 41 & 3383 & $+41.5 \%$ \\
4 & 840 & 52 & 2474 & $+3.5 \%$ & 592 & 38 & 3514 & $+47.0 \%$ \\
8 & 834 & 49 & 2505 & $+4.8 \%$ & 582 & 36 & 3578 & $+49.7 \%$ \\
16 & 831 & 48 & 2520 & $+5.4 \%$ & 576 & 35 & 3610 & $+51.0 \%$ \\
32 & 832 & 45 & 2526 & $+5.7 \%$ & 573 & 35 & 3626 & $+51.7 \%$ \\
\hline
\end{tabular}

between 0 and 20. Given $n$ segments, $400 / n$ customers with the lowest reservation price $p_{1}^{n}=20 / n$ are assigned to the first segment, the next $400 / n$ customers to segment 2 , and so on. Each buy-back price, thus, indicates the value for which all customers of a respective segment would sell their broken products. The segmentation of customers is sketched in Figure 2. The corresponding trade-in prices $\hat{p}_{i}$ are determined by adding $p_{s}$ to the respective segments' buy-back prices.

Table 4 depicts the results of the experiments which can be interpreted as follows. For both strategies (optimal trade-in and buy-back), a more detailed segmentation increases the total profit $\Pi_{T I / 1}$, since take back occurs in smaller batch sizes allowing for a more focused control of the install base. However, a repeated doubling of the number of customer segments has a decreasing impact on profit. The final order $F O_{T I / 1}$ decreases as less spare parts are sold compared to the benchmark case. This observation corresponds to an earlier start of the trade-in/buy-back activities $\left(z_{T I / 1}\right)$.

Comparing the optimal strategies, one finds a substantial difference in the percentage gains. This is attributed to a more direct control of spare parts demand when buying back broken products. In contrast to trade-in each unit bought back immediately decreases demand for spare parts by one in addition to the common reduction of future demands by lowering the install base. The trade-in strategy additionally bears the burden of having 


\section{International Journal of Production Research}

to take back a whole segment at once. Buy-back, on the other hand, only applies to the fraction of the considered segment that actually induces demand for spare parts and thus, in general total profit cannot be smaller than when applying a trade-in strategy.

For instance, in the case of 32 segments the total trade-in quantity equals to 91 (in TI) while 165 broken products are bought back (in M1). This reduces the total spare parts sales from 1870 in the benchmark solution by 206 (11\%) in TI but by 559 (30\%) in M1. Since the buy-back strategy reduces the final order by $39 \%$ in contrast to only $11 \%$ with trade-in, the decrease in sales is overcompensated by a larger reduction in final order related production and stock-keeping cost.

\section{Robustness with respect to exogenous constraints and parameters}

In this section, we focus on elaborating the impact of several assumptions that might limit the practical applicability of buy-back strategies. Furthermore, we isolate parameters that play an important role on the profitability of buying back broken products.

\subsection{Buy-back related exogenous constraints}

In industry problems arise due to possibly existing exogenous constraints, such as communication, information, and pricing related constraints. In the basic model M1, the OEM is able to offer each customer individually a buy-back and has therefore the flexibility to decide on the quantity he buys back in each planning period. Quantity flexibility can be limited if (like in the trade-in case) the buy-back is proposed to all customers simultaneously via a mass-media marketing campaign. As the OEM cannot withdraw his offer, he has to accept all broken products the customers wish to sell.

The OEM can face information constraints if he cannot assign a customer to her corresponding segment and does hence not know from which segment a broken product originates. In the marketing literature, a number of market-segmentation approaches distinguish between observable and unobservable characteristics (see, e.g., Kotler and Keller 2008, Wedel and Kamakura 2000). Observable criteria are mostly geographic or demographic data. Additionally, the type of relationship like B2B (car rental enterprise) or B2C (private customer) could be used. Unobservable criteria typically contain psychographic or behavioral characteristics that cannot be used to discriminate between customers.

Finally, the OEM can face limited pricing flexibility. Pricing constraints describe the OEM's restriction to address each segment individually. Therefore, the OEM might be limited to set only one price per period. In this case, he is not able to buy back products from different segments for different prices in a given period. Bernstein et al. (2006) give an overview on reasons why an OEM is restricted in his pricing format.

These three dimensions, namely pricing and quantity flexibility as well as individual information availability result in eight subclasses of problems (see Table 5). However, it can be shown that several subclasses are redundant (shaded cells). First, the OEM is not able to exploit pricing flexibility if he cannot assign his customers to the respective segments, as every customer will apparently claim to have a high reservation price (this excludes A and C). Second, if the OEM communicates segment specific buy-back prices via mass-media marketing campaigns, this is usually done by proposing an 'up-to' price. If (as is the case in B) individual information is available, actual prices offered to the customers can be used to regain quantity flexibility. This could be done by proposing 
Table 5. Three dimensions of flexibility and information availability

\begin{tabular}{|c|c|c|c|c|c|}
\hline & \multirow[b]{3}{*}{$\begin{array}{l}\text { individual } \\
\text { information }\end{array}$} & \multicolumn{4}{|c|}{ quantity flexibility } \\
\hline & & \multicolumn{2}{|c|}{ yes } & \multicolumn{2}{|c|}{ no } \\
\hline & & available & not avail. & available & not avail. \\
\hline \multirow{2}{*}{ 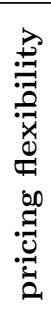 } & yes & $\begin{array}{l}\text { full pricing and } \\
\text { quantity flexibility, } \\
\text { full information } \\
\text { availability (M1) }\end{array}$ & A & B & $\mathrm{C}$ \\
\hline & no & $\begin{array}{l}\text { limited pricing and } \\
\text { full quantity flex- } \\
\text { ibility, full infor- } \\
\text { mation availability } \\
\text { (M2) }\end{array}$ & $\begin{array}{l}\text { limited pricing and } \\
\text { full quantity flexi- } \\
\text { bility, limited infor- } \\
\text { mation availability } \\
\text { (M3) }\end{array}$ & \multicolumn{2}{|c|}{ 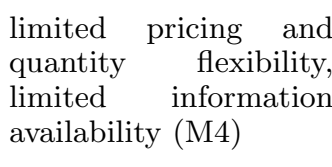 } \\
\hline
\end{tabular}

too low prices as soon as the designated buy-back quantity is reached. Then, a setting results which is comparable to M1. Finally, individual information is not useful if there is neither pricing nor quantity flexibility (M4).

There are three relevant subclasses of problems (M2-M4) when deviating from the idealized setting M1. Subsequently, the economic impact of these assumptions is assessed. For this, model M1 needs to be adapted which is described in the next subsection.

\subsection{The economic impact of exogenous constraints}

Setting M2 is characterized by a restricted pricing flexibility, i.e. only a single buy-back price can be set in each period. However, this setting allows to assign each customer to her segment and to choose which quantity to buy from which customer segment. The OEM's pricing decision is described, as in Section 3, by a binary decision variable $\Theta_{i, t}$ that determines the OEM's buy-back price in period $t$. In order to implement setting M2, constraints (11), (13), and (14) have to be added to the original setting M1. Obviously, due to the additional restrictions imposed the optimal profit for M2 (denoted by $\Pi_{2}$ ) cannot exceed the optimal profit for M1.

In setting M3, the absence of available information regarding each customer's assignment results in the problem that it cannot be easily determined how many items were bought back from which customer segment. Further assumptions are required to keep track of the number of customers in each segment. However, the profit must lie between the profits of the less restricted setting M2 and the even more restricted setting M4. A more detailed analysis of this setting will be left for future research.

Setting M4 provides us with the least flexible buy-back environment that still allows for customer segmentation. Due to its limited pricing flexibility only a single price can be selected per period. All customers with a reservation price smaller than the offered price return their dysfunctional product to the OEM. Constraint (12) is replaced by

$$
\lambda \cdot y_{i, t-1}-x_{i, j, t} \leq M \cdot\left(1-\Theta_{j, t}\right) \quad i, j=1, \ldots, n \quad i \leq j \quad t=1, \ldots, T .
$$

Constraint (15) captures the fact that for a given buy-back price $p_{j}$ (i.e. $\Theta_{j, t}=1$ ) all customers from segments $i=1, \ldots, j-1$ are going to sell their broken products.

By solving the respective optimization problems M2 and M4 for $n=2$ segments, the economic impact of the limitations regarding pricing and quantity flexibility as well as 
Table 6. Total discounted profit, relative deviation from M1 and corresponding final order sizes.

\begin{tabular}{lcccc}
\hline & Benchmark & M1 & M2 & M4 \\
\hline Final order size $F O$ & 935 & 621 & 622 & 626 \\
First buy-back period $z$ & - & 42 & 41 & 41 \\
Total discounted profit I & 2390 & 3383 & 3358 & 3343 \\
Relative deviation from Benchmark $\Delta$ & - & $+41.6 \%$ & $+40.5 \%$ & $+39.9 \%$ \\
\hline
\end{tabular}

information availability can be evaluated. In Table 6 , the total discounted profits and the final order sizes are presented for all settings. Interestingly, while showing in general the same solution structure with three phases as M1, the third (buy-back) phase of both settings M2 and M4 is characterized by switching price decisions. While in most periods the low price $p_{1}$ is set and defective products from the first customer segment are bought back only, sporadically the larger price $p_{2}$ is set. In those 'campaign' periods a stock of broken products is build up, i.e. more broken products are bought back than are actually needed to satisfy the current period's demand. For a detailed description of the policy structure see Kleber et al. (2009).

The comparably small gap between M1, M2, and M4 can be explained by the similarity of the optimal solution structures. First, it can be observed that the different limitations do not influence the final order size substantially. Second, changes in the solution structure occur quite late in the planning horizon as indicated in Table 6 by the first buy-back period $z$. As all cash flows are discounted, a deviation in one of the later periods only has a limited effect on the total discounted profit.

It seems that the OEM can significantly enhance his performance by including buybacks into the decision making process. This result also holds when comparing M4 with the trade-in solution described in Section 3.3. Although both model settings are comparable, the impact of a focused buy-back and (to a smaller extent) of price differences is substantial. The following subsection aims to provide insights into the robustness of these findings.

\subsection{Sensitivity to changing parameters}

Taking the base case from Section 3 with two segments as starting point, a sensitivity analysis is performed that focuses on elaborating which parameters especially affect the buy-back profitability. To achieve this, all relevant parameters are modified to a considerably higher and lower value while keeping all other parameters constant. We start our discussion with a comparison of M1 and the benchmark solution before presenting the specific characteristics of settings M2 and M4. All results can be found in the Appendix. Table 7 presents the parameters that seem to have a substantial impact on the profitability of the buy-back option, i.e. the remanufacturing yield rate $q$, the interest rate $r$, the final lot unit cost $c_{f}$, the length of the planning horizon $T$ as well as both holding cost parameters $h^{R}$ and $h^{S}$.

The findings can be interpreted as follows. In the benchmark setting, both spare parts demand and recoverables supply are not actively controlled by the OEM. As serving customers close to the end of the planning horizon becomes more and more expensive, profitability gains of buying back broken products (in M1) increase since (in contrast 


\section{Page 13 of $18 \quad$ International Journal of Production Research}

Table 7. Optimal final order $F O$, discounted profit $\Pi$, first buy-back period $z$ and relative profit change $\Delta$ in the benchmark solution and M1 for parameters with significant impact.

\begin{tabular}{|c|c|c|c|c|c|c|c|}
\hline & & \multicolumn{2}{|c|}{ Benchmark } & \multicolumn{4}{|c|}{ Optimal buy-back in M1 } \\
\hline & & $F O_{B M}$ & $\Pi_{B M}$ & $F O_{1}$ & $z_{1}$ & $\Pi_{1}$ & $\Delta_{1}$ \\
\hline \multicolumn{2}{|c|}{ base case } & 935 & 2390 & 621 & 42 & 3383 & $+41.6 \%$ \\
\hline \multirow{6}{*}{$q$} & $40 \%$ & 1122 & 836 & 689 & 36 & 2415 & $+188.7 \%$ \\
\hline & $50 \%$ & 935 & 2390 & 621 & 42 & 3383 & $+41.6 \%$ \\
\hline & $60 \%$ & 748 & 3821 & 541 & 47 & 4396 & $+15.1 \%$ \\
\hline & $1.25 \%$ & 935 & 4142 & 758 & 55 & 4513 & $+8.9 \%$ \\
\hline & $2.5 \%$ & 935 & 2390 & 621 & 42 & 3383 & $+41.6 \%$ \\
\hline & $5 \%$ & 935 & 567 & 462 & 29 & 2287 & $+303 \%$ \\
\hline \multirow{3}{*}{$c_{f}$} & 1.5 & 935 & 3793 & 724 & 48 & 4369 & $+15.2 \%$ \\
\hline & 3 & 935 & 2390 & 621 & 42 & 3383 & $+41.6 \%$ \\
\hline & 4.5 & 935 & 986 & 553 & 36 & 2510 & $+154.4 \%$ \\
\hline \multirow{3}{*}{$T$} & 60 & 795 & 3156 & 628 & 42 & 3454 & $+9.4 \%$ \\
\hline & 80 & 935 & 2390 & 621 & 42 & 3383 & $+41.6 \%$ \\
\hline & 100 & 1039 & 1644 & 610 & 41 & 3371 & $+105 \%$ \\
\hline \multirow{3}{*}{$h^{S}$} & 0.15 & 935 & 2868 & 652 & 45 & 3604 & $+25.7 \%$ \\
\hline & 0.2 & 935 & 2390 & 621 & 42 & 3383 & $+41.6 \%$ \\
\hline & 0.25 & 935 & 1912 & 587 & 39 & 3185 & $+66.6 \%$ \\
\hline \multirow{3}{*}{$h^{R}$} & 0.05 & 935 & 3210 & 674 & 47 & 3816 & $+18.9 \%$ \\
\hline & 0.1 & 935 & 2390 & 621 & 42 & 3383 & $+41.6 \%$ \\
\hline & 0.15 & 935 & 1789 & 576 & 38 & 3108 & $+73.7 \%$ \\
\hline
\end{tabular}

to the benchmark) it can react properly to changing parameters. This is the case if the remanufacturing yield rate $q$ decreases or if the interest rate $r$, the final order unit cost $c_{f}$ or one of both holding cost parameters become larger. A larger $h^{S}$, for instance, creates the incentive to start buying back earlier which reduces the number of spare parts procured in the final order. Regarding the length of the planning horizon $T$, a longer planning horizon reduces the profits substantially if the buy-back option is neglected. When incorporating the buy-back option into the spare parts fulfillment strategy, however, even longer service periods can be offered while keeping the costs for this additional service at a moderate level.

All other parameters affect the advantageousness of the buy-back option only slightly. Increasing one of the outflow rates $\left(\nu_{1}, \nu_{2}\right)$ or one of the the buy-back prices $\left(p_{1}, p_{2}\right)$ decreases the performance gain of M1. In the first case, total demand for spare parts decreases and in the second, an active demand control becomes more expensive. Changing the composition of the install base by altering the initial segment sizes $\left(\bar{y}_{1}, \bar{y}_{2}\right)$ results in similar effects as buy-back price modifications, i.e. increasing the number of customers in segment two augments the average price of a buy-back. Interestingly, the relative deviation $\Delta_{1}$ remains constant if the number of customers in both segments is multiplied by the same factor. A change in the failure rate $\lambda$, on the other hand, does not have a large impact as all decisions are increased or decreased approximately proportionally. Furthermore, the cost of remanufacturing broken products $c_{r}$ has no substantial influence.

Regarding model settings M2 and M4 it is to be said that the profit loss from re- 


\section{\begin{tabular}{ccc} 
December 13, 2010 & $10: 49$ & International Journal of Production Research $\quad$ KleSchuVoi IJPR \\
\hline
\end{tabular}

stricted information availability and/or quantity and pricing flexibility is quite robust with respect to parameter changes. The largest loss in total profit observed when comparing settings M4 and M1 is $2.7 \%$ in a situation with a large remanufacturing yield rate $q=60 \%$.

\section{Conclusions}

Due to its high profitability, after-sales management has received an ever increasing attention in the recent past. This study was particularly motivated by the automotive industry which guarantees to supply spare parts for their cars over a long period. These guarantees are an attractive instrument for the marketing and sales department while they impose a challenge for spare parts management. A favorable sourcing option is provided by remanufacturing broken parts obtained in exchange for spare parts. In the case of considerable yield losses, however, it should be complemented by other sources like a final order placed at the end of regular production. This option bears the burden of large holding cost over a long planning horizon, making demand satisfaction expensive especially during late periods of the final phase. To avoid this problem, options like trade-in or buy-back of the whole product are considered that release the OEM from his obligation to deliver spare parts.

For evaluating both strategies basic MILP models have been developed. A numerical example was used to compare the potential gains of both strategies. It revealed that both strategies can be beneficial for the OEM while the buy-back strategy outperforms a trade-in strategy as it specifically focuses on taking back broken products. In a sensitivity analysis, parameters have been identified that especially influence the profitability of the buy-back option. It seems that there is a rather limited impact of buy-back related parameters whereas those parameters determining the profit impact of the final order size (like unit production cost and holding cost) appear to be of highest importance. In case of a high remanufacturing yield rate, the system can be handled like a repair system (see, e.g., Sherbrooke 2004) where the buy-back option is less favorable. If the planning horizon is extended, stock-keeping of final order produced parts becomes more costly and thus, the OEM benefits to a larger extent from compensating the customers for not fulfilling the spare parts availability guarantee.

To our knowledge, this study is the first attempt to investigate the value of buying back broken products for spare parts management. There are certainly some limitations to this study which can be overcome by further research. The model could be extended into several directions. Several parameters (like e.g. the failure rate) are likely to change over time or can differ between customer segments. Segment specific quality levels of recoverables would impact remanufacturing cost and yield rates. Another extension would be that multiple parts are included in a product and thus, a product bought back would yield inflows of several remanufacturable parts. Furthermore, segmenting the install base could also be used to price discriminate between consumers when selling spare parts. This would entail a shift towards buying back from segments showing lower spare parts prices.

In contrast to the MILP approach, general structural properties of optimal solutions could be obtained by using optimal control methods, as have been successfully applied in product recovery systems (see Kiesmüller et al. 2004, Kleber 2006). Finally, complementing our deterministic approach, a stochastic simulation could be used to evaluate more realistic models involving uncertainty. Here, due to the high flexibility, buying back 


\section{Page $\mathbf{1 5}$ of $\mathbf{1 8}$ \\ International Journal of Production Research}

International Journal of Production Research

broken products becomes an even more attractive option.

\section{References}

Bernstein, F., Chen, F., and Federgruen, A., 2006. Coordinating supply chains with simple pricing schemes: The role of vendor-managed inventories. Management Science, 52 (10), 1483-1492.

Cohen, M.A., Agrawal, N., and Agrawal, V., 2006. Winning in the Aftermarket. Harvard Business Review, 84 (5), 129-138.

Gal-Or, E., 1989. Warranties as a signal of quality. Canadian Journal of Economics, 22, $50-61$.

Hesselbach, J., Mansour, M., and Graf, R., 2002. Reuse of components for the spare parts management in the automotive electronics industry after end-of-production. 9th CIRP International Seminar, Erlangen, Germany.

Huiskonen, J., 2001. Maintenance spare parts logistics: Special characteristics and strategic choices. International Journal of Production Economics, 71, 125-133.

Inderfurth, K. and Mukherjee, K., 2008. Decision Support for Spare Parts Acquisition in Post Product Life Cycle. Central European Journal of Operations Research, 16, 17-42.

Inderfurth, K. and Kleber, R., 2009. Modellgestützte Flexibilitätsanalyse von Strategien zur Ersatzteilversorgung in der Nachserienphase. Zeitschrift für Betriebswirtschaft, 79, 1019-1049 (in German).

Kennedy, W.J., Patterson, J.W., and Fredendall, L.D., 2002. An overview of recent literature on spare parts inventories. International Journal of Production Economics, 76, 201-215.

Kiesmüller, G.P., Minner, S., and Kleber, R., 2004. Managing dynamic product recovery: An optimal control perspective. In: R. Dekker, M. Fleischmann, K. Inderfurth and L.N. Van Wassenhove, eds. Reverse Logistics: Quantitative Models for Closed-Loop Supply Chains. Berlin: Springer, 221-247.

Kim, B. and Park, S., 2008. Optimal pricing, EOL (end of life) warranty, and spare parts manufacturing strategy amid product transition. European Journal of Operational Research, 188, 723-745.

Kleber, R., 2006. Dynamic Inventory Management in Reverse Logistics. Lecture Notes in Economics and Mathematical Systems 574 Berlin: Springer.

Kleber, R. and Inderfurth, K., 2007. Heuristic Approach for Inventory Control of Spare Parts after End-of-Production. In: A. Otto and R. Obermaier, eds. Logistikmanagement - Analyse, Bewertung und Gestaltung logistischer Systeme. Wiesbaden: DUV, 185-200.

Kleber, R., Schulz, T., and Voigt, G. 2009. Dynamic buy-back for product recovery in endof-life spare parts procurement. FEMM Working Paper No 26/2009, Otto-von-Guericke University Magdeburg, Germany.

Kotler, P. and Keller, K., 2008. Marketing Management. 13th edition, London: Pearson Prentice Hall.

Minner, S. and Kiesmüller, G.P., 2010. Dynamic Product Acquisition in Closed Loop Supply Chains. International Journal of Production Research, to appear.

Pourakbar, M., Frenk, J.G.B., and Dekker, R., 2009. End-of-life inventory decisions for consumer electronics service parts. Econometric Institute Report Series EI2009-48, Erasmus School of Economics, Erasmus University Rotterdam.

Ray, S., Boyaci, T., and Aras, N., 2005. Optimal Prices and Trade-in Rebates for Durable, Remanufacturable Products. Manufacturing 85 Service Operations Management, 7 (3), 
208-228.

Sherbrooke, C.C., 2004. Optimal Inventory Modeling of Systems. Second New York, NY.: Wiley.

Spence, M., 1977. Consumer misperceptions, products failure and producer liability. Review of Economic Studies, 44, 561-572.

Thierry, M., et al., 1995. Strategic Issues in Product Recovery Management. California Management Review, 37 (2), 114-135.

Wedel, M. and Kamakura, W., 2000. Market Segmentation: Conceptual and Methodological Foundations. 2nd edition, Boston: Kluwer.

\section{Appendix}




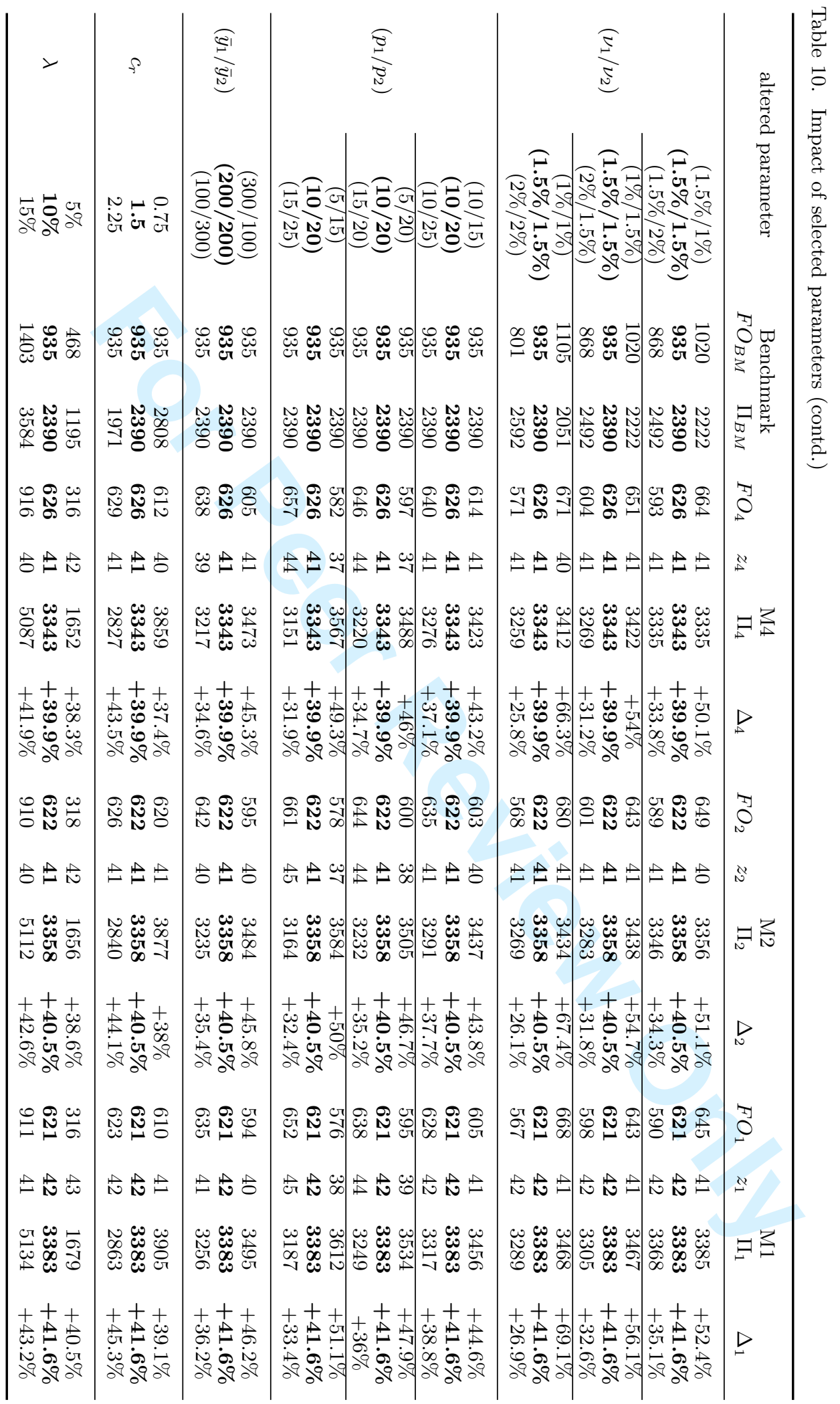

